\title{
The Council of Europe's Reference Framework of Competences for Democratic Culture: Policy context, content and impact
}

Martyn Barrett

\section{How to cite this article}

Barrett, M. (2020) 'The Council of Europe's Reference Framework of Competences for Democratic Culture: Policy context, content and impact'. London Review of Education, 18 (1): 1-17. https://doi.org/10.18546/LRE.18.1.01

Submission date: 1 May 2019

Acceptance date: 3 September 2019

Publication date: 1 March 2020

\section{Peer review}

This article has been peer reviewed through the journal's standard double-blind peer review, where both the reviewers and authors are anonymized during review.

\section{Copyright}

(C) Copyright 2020 Barrett. This is an Open Access article distributed under the terms of the Creative Commons Attribution Licence (CC BY) 4.0 https://creativecommons.org/licenses/by/4.0/, which permits unrestricted use, distribution and reproduction in any medium, provided the original author and source are credited.

\section{Open access}

London Review of Education is a peer-reviewed open-access journal. 


\title{
The Council of Europe's Reference Framework of Competences for Democratic Culture: Policy context, content and impact
}

\author{
Martyn Barrett* - University of Surrey, UK
}

\begin{abstract}
The Council of Europe's Reference Framework of Competences for Democratic Culture (RFCDC) was published in April 2018, and is currently being implemented in a number of Council of Europe member states. The RFCDC consists of three main components: a conceptual model of the competences that learners need to acquire in order to respond appropriately and effectively to democratic and intercultural situations; validated and scaled descriptors and learning outcomes for all of the competences in the model; and guidance for ministries of education and education practitioners on curriculum, pedagogy, assessment, teacher education, the whole-school approach, and building learners' resilience to radicalization. This article describes the policy background that motivated and accompanied the development of the RFCDC, and the process through which it was developed. It also provides an overview of the contents of the RFCDC, and an explanation of the impact that the framework is beginning to have on Council of Europe actions in the sphere of formal education.
\end{abstract}

Keywords: citizenship education, human rights education, intercultural education, competence-based education, intercultural dialogue

The Council of Europe's Reference Framework of Competences for Democratic Culture (RFCDC) (Barrett et al., 2018a, 2018b, 2018c) was launched in April 2018, heralding a new approach to education for democratic citizenship and human rights education (EDC/HRE) by the Council of Europe (CoE). The RFCDC provides a comprehensive reference framework covering EDC/HRE and intercultural education (IE), and it is currently being viewed by the CoE as the primary vehicle through which $\mathrm{EDC} / \mathrm{HRE}$ and IE can be implemented within member states. For this reason, new actions have recently been undertaken by the CoE to encourage and support the implementation of the RFCDC in the member states. There are 47 member states of the CoE. In addition, the CoE's education activities are open to Belarus, the Holy See and Kazakhstan (as additional signatories of the European Cultural Convention). Thus, the CoE is encouraging and supporting implementation of the RFCDC in 50 countries in total.

This article provides an overview of the policy context that motivated and accompanied the development of the RFCDC, and the process through which it was developed. It also provides an overview of the main contents of the RFCDC, and a discussion of the impact that the framework is beginning to have on CoE actions in the sphere of formal education. 


\section{The policy context leading to the RFCDC}

There were two main policy strands that eventually led to the establishment, in 2013, of a CoE expert group tasked with developing a new comprehensive reference framework for citizenship education. The first of these policy strands was the CoE's existing work in the field of EDC/HRE. The overall mission of the CoE is to promote and protect human rights, democracy and the rule of law, and it functions as the European watchdog on these issues (through the production of monitoring reports on the member states) and as the protector of European citizens' human rights (through the activities of the European Court of Human Rights). The CoE views EDC/HRE as a vital tool for promoting and protecting democracy, human rights and the rule of law within the member states.

Work on EDC/HRE was initiated at the Second Summit of Heads of State and Government of the Council of Europe in 1997, which gave the CoE a mandate to pursue activities in this field. The EDC/HRE programme developed concepts, methods, practices, materials and policies for EDC/HRE, supported grass-roots projects, and established a network of member state coordinators for EDC/HRE. These various activities culminated in 2010 with the production of a comprehensive unifying policy document, the Charter on Education for Democratic Citizenship and Human Rights Education (CoE, 2010). The text of the Charter was approved in May 2010 as a formal recommendation by the Committee of Ministers (the CoE's most senior decision-making body, consisting of the foreign ministers of the member states). This recommendation stated that all member states should include EDC/HRE in the curricula for formal education at pre-primary, primary and secondary school levels as well as in general and vocational education and training.

A substantial body of practical materials was produced under the aegis of the EDC/HRE programme. These included both an EDC/HRE Pack and a set of manuals on Living Democracy. The EDC/HRE Pack consists of publications addressed to policymakers, teacher trainers, school directors, school inspectors, universities and civil society organizations (for example, Bäckman and Trafford, 2007; Bîrzea et al., 2005; Kerr et al., 2010). The manuals on Living Democracy are instead aimed at teachers. These manuals provide high-quality lesson materials that have been tested in multiple countries, and are designed to be sufficiently flexible to enable teachers to teach EDC/ HRE in an interactive and challenging manner at both primary and secondary school levels (for example, Gollob et al., 2010a, 2010b; Gollob and Krapf, 2008).

The EDC/HRE programme formed the first policy strand leading up to the RFCDC. The second policy strand emerged from the development of interculturalism as the CoE's preferred policy approach for responding to the challenges associated with culturally diverse democratic societies. The arguments for an interculturalist approach were developed in response to the growing political disenchantment with multiculturalism (Cameron, 2011; Merkel, 2010; Sarkozy, 2011). There was a widespread perception that multiculturalism had failed because it had encouraged different cultural groups to live in parallel communities that did not interact with one another, and because it had weakened collective national identities within countries (for a discussion, see Barrett, 2013). The interculturalist paradigm was conceived as an alternative to multiculturalism. The arguments in favour of interculturalism were laid out explicitly in the CoE's White Paper on Intercultural Dialogue (CoE, 2008), the contents of which were unanimously endorsed by the Committee of Ministers (Bunjes, 2013).

The CoE's approach to interculturalism is based on universal human rights, shared fundamental values, respect for common heritage, respect for cultural diversity 
and respect for the equal dignity of every individual. Intercultural dialogue is accorded a central role in this approach because it allows national, ethnic, linguistic, religious and other divides to be bridged on the basis of the shared universal values of dignity and human rights. However, the White Paper argues that intercultural dialogue can only flourish within a society if democratic citizenship and participation are strengthened, if spaces for intercultural dialogue are created and opened up to all, and if intercultural competences are taught and learned through the formal education system. In other words, the White Paper accorded a key role to education - education systems have to be harnessed so that they equip citizens with the competences that are required for intercultural dialogue. These conclusions were reinforced in the subsequent Report of the Group of Eminent Persons (CoE, 2011), which, in its final recommendations, specifically urged educators and education authorities in the member states to ensure that intercultural competence was included as a core element of their school curricula.

In response to this call for action, several practical initiatives were undertaken by the CoE to develop teaching materials for promoting the intercultural competence of learners in primary, secondary and higher education (for example, Barrett et al., 2013; Byram et al., 2009; Byram et al., in press). In addition, a guidance document on Developing Intercultural Competence through Education (Barrett et al., 2014) was produced.

\section{The decision to develop the RFCDC}

These two policy strands relating to EDC/HRE and IE were pursued by the CoE independently of one another. However, this situation changed when the member state of Andorra took up the Chairmanship of the Committee of Ministers in November 2012. Andorra made education the priority of its political and policy programme. To this end, it launched a process of reflection on how education may be used to create the conditions required for living peacefully together with others in culturally diverse democratic societies. The Andorran initiative was focused through a Chairmanship conference that was held in Andorra la Vella in February 2013, at which the role of education in promoting learners' competences for a culture of democracy and for intercultural dialogue was discussed. The conference also explored a proposal to develop a unifying comprehensive reference framework that would describe the competences required for both democratic culture and intercultural dialogue together.

As the general rapporteur observed (Van't Land, 2013), the Andorran conference was an unprecedented event, not only because education was chosen for the first time as the theme for a conference by the Chairmanship of the Committee of Ministers, but also because it focused on EDC, HRE and IE, none of which had been selected as the central theme of a chairmanship or presidency at European level before. In its deliberations, the conference agreed on the importance of developing a common reference framework for democratic and intercultural competences that could empower education practitioners in promoting a culture of democracy and intercultural dialogue within the member states, and a strong political will to pursue this objective was expressed.

This consensus was communicated to the 24th Session of the Council of Europe Standing Conference of Ministers of Education (in which the education ministers of all the member states participate), which took place in Helsinki in April 2013. The ministers of education translated the consensus into a formal recommendation, calling on the Committee of Ministers to instruct the CoE's Steering Committee for Educational Policy and Practice (CDPPE) to consider developing 'a reference framework to assist 
member States in implementing a competence-based education for democracy and intercultural dialogue' (CoE, 2013a, paragraph 21.4).

The CDPPE is the body that oversees all of the CoE's programmes in the field of education. All member states are represented on the committee by senior officials from the education sector, usually senior civil servants from the national ministry of education. There are two representatives from each member state on the committee. In addition to overseeing the CoE's education programmes, the CDPPE has a mission to promote reforms of education systems and policies in the member states that will help to advance the core values of the CoE (that is, human rights, democracy and the rule of law). The Helsinki recommendation from the ministers of education was discussed and strongly supported at a meeting of the CDPPE that took place in Belgrade in October 2013.

\section{The activities of the RFCDC expert group}

An ad hoc expert group was therefore established to undertake the task of developing the reference framework. This group was constituted in such a way that it drew experts from every area of activity in the CoE's Education Department, including EDC/HRE, IE, history education, language education, higher education and teacher education. There was also a representative from the European Wergeland Centre (a joint CoE-Norwegian Government resource centre for EDC/HRE and IE) and from the CDPPE itself.

The expert group met for the first time in Strasbourg in December 2013. The group was given the mandate to develop a reference framework of competences for democratic culture and intercultural dialogue, including descriptors (that is, indicators and learning outcomes) for all of the competences contained in the framework. In order to achieve this goal, the working group met at regular intervals, typically four or five times per year. At each meeting, reports of work that had been conducted since the previous meeting were discussed, and decisions were made about the next block of work that needed to be executed. The work itself was carried out by the experts between the meetings.

Importantly, the CDPPE meeting in Belgrade had made several recommendations to the expert group concerning its mandate. In addition, throughout the process of developing the framework, the expert group reported to the CDPPE twice per year, and on these occasions, it also received feedback from CDPPE members. This dialogical method ensured that the framework that was eventually developed met the needs of the member states' ministries of education.

One specific instruction that was given to the expert group by the CDPPE was that the framework should take the Common European Framework of Reference for Languages (CEFR) (CoE, 2001) as its model. The CEFR specifies five broad areas of language competence (listening, reading, spoken interaction, spoken production and writing), as well as a set of specific competences that are required for effective language use (for example, lexical competence, grammatical competence and phonological competence). Proficiency in these various competences is specified through descriptors (expressed as 'can do' statements) at six levels, ranging from basic through to proficient. The CEFR therefore enables users to produce individualized language competence profiles in terms of what a person 'can do' in considerable detail. Since its publication in 2001, the CEFR has been adopted globally as a tool for characterizing and assessing the language competences of learners (Byram and Parmenter, 2012). Due to the authoritative status of the CEFR, the CDPPE asked 
the RFCDC expert group to construct an analogous reference framework covering democratic and intercultural competences.

In addition, the CDPPE recommended that the expert group should start with what was already a common basis across EDC/HRE and IE, and draw on the best existing work that was available, rather than invest effort in 'reinventing the wheel'. It also suggested that the expert group should draw on work by actors in other sectors (especially the youth sector), ensure that the framework was linked directly to learning outcomes that could be used in the classroom, and ensure that the framework covered all age groups and all levels of education.

The expert group began its work by conducting an audit of existing conceptual schemes of democratic, civic and intercultural competence. In total, 101 such schemes were audited. It was found that these schemes contained 55 different competences. In order to reduce this list to a more manageable and practical length, a set of principled criteria was devised for identifying the core competences with which learners need to be equipped through education. The application of these criteria led to the identification of 20 key competences. These were then used to build a new competence model that was more comprehensive than any of those that had been audited. (For a full description of how the model was constructed, see Barrett, 2016a.)

While this work was proceeding, external political events overtook the timetable that was being followed by the expert group. On 7 January 2015, in a terrorist attack on the Charlie Hebdo offices in Paris, 12 people were killed, and a further 11 people injured. Related terrorist attacks subsequently took place in the Île-de-France region between 7 and 9 January, including an attack at a Jewish supermarket in Paris in which a further four people were killed. The shockwaves from these acts of terrorism led to a meeting of senior officials at the $\mathrm{CoE}$, at which it was agreed that the organization needed to draw up an action plan on combatting radicalization leading to violent extremism and terrorism.

The expert group was scheduled to hold a regular meeting in Strasbourg on 19-20 January 2015, but the agenda was rearranged at short notice to enable the CoE's Director General for Democracy Snežana Samardžić-Marković to address the group. She briefed the group on the intentions for the action plan, and informed the group that education would feature as one of the central components of the plan, with the RFCDC forming the core element of this component. The expert group was asked to accelerate the progress of its work, so that concrete products could be made available by the end of 2015. Given that it had taken ten years to develop the CEFR, this request elicited some concern within the expert group. Nevertheless, in discussion with the secretariat, a new timetable for the project was drawn up, which entailed completing the development of the competence model before the end of 2015 and embarking on the development of descriptors immediately. The CoE (2015)'s 'The fight against violent extremism and radicalisation leading to terrorism - action plan' was formally adopted by the Committee of Ministers in May 2015, with the RFCDC being assigned a core role in the plan.

A first draft of the competence model, based on the 20 competences that had emerged from the audit, was produced in February 2015. This draft was submitted to an international consultation with academic experts, education practitioners and policymakers, including experts nominated by the education ministries of the CoE's member states. The model received strong endorsement in the consultation, and the feedback that was received was used to fine-tune and finalize the model. The model was completed and signed off by the CDPPE in December 2015. Meanwhile, 
work was simultaneously proceeding on developing and empirically validating the descriptors for the framework. In January 2016, additional work began on writing guidance chapters on how the competence model and the descriptors could be used by education policymakers and practitioners.

The model of competences (Barrett, 2016a) was published in April 2016, and was formally launched and showcased to the education ministers of the member states at the 25th Session of the Council of Europe Standing Conference of Ministers of Education. The conference took place in Brussels, against the background of further terrorist atrocities that had taken place in that city on 22 March 2016, in which 32 people had been killed and more than 300 injured. The ministers recognized the potential of the framework for building resilience to radicalization in young people, and for equipping them with the competences that are required to live peacefully with others with full respect for the dignity and rights of others. The Final Declaration of the conference, which the education ministers unanimously agreed, strongly endorsed the framework and called on the CoE (2016) to assist member states in examining and implementing the framework in their national education systems.

Intensive work on the reference framework continued over the following 18 months. A major focus was the development of the descriptors. This work had begun in the previous year, when 2,085 draft descriptors had initially been written. These descriptors were subsequently evaluated using a series of rating tasks, validation tasks and scaling tasks that involved 3,094 teachers across Europe who were recruited through the education ministries of member states. The data were used to identify the descriptors that received the highest ratings from the teachers on a number of criteria, including the clarity of their wording, their observability in educational settings, and their usefulness for assessing the target competences. Teachers were also asked to use subsets of the descriptors for rating individual learners, on the basis of which the descriptors were then statistically scaled to three different levels of proficiency basic, intermediate and advanced. Through these processes, 447 highly rated scaled descriptors covering all 20 competences in the model were identified. Of these, 135 were classified as key descriptors on the basis of the scaling data and their wording. Work on the bank of validated descriptors was completed in June 2017.

At the same time, work continued on the guidance chapters. It was decided that six chapters were required, on curriculum, pedagogy, assessment, teacher education, the whole-school approach, and radicalization leading to violent extremism and terrorism. Assessment had emerged at various conferences and meetings as a particularly sensitive and controversial topic, insofar as the competence model included both values and attitudes - the implication being that learners' values and attitudes would need to be assessed. For this reason, a 'hearing' on assessment was held in Strasbourg in October 2016, to receive views from relevant stakeholders, including experts in educational assessment (Barrett, 2016b). The discussions that took place at the hearing were subsequently used to inform the guidance that was written on assessment for the framework.

Work on writing the six guidance chapters was completed by September 2017, and the manuscript of the full reference framework, consisting of three volumes (one on the competence model, one on the descriptors, and one on the guidance for policymakers and practitioners), was also finalized in that month. The manuscript was presented to the education ministries of the member states at the 8th Prague Forum on Education Reforms in Europe, which took place in Prague in October 2017. The three volumes of the RFCDC (Barrett et al., 2018a, 2018b, 2018c) were subsequently published 
and launched at the Council of Europe Conference of the Danish Chairmanship of the Committee of Ministers, which was held in Copenhagen in April 2018.

The framework that emerged from this process provides a comprehensive competence-based approach to EDC, HRE and IE. It offers detailed proposals on how formal education - ranging all the way from pre-school through to university level can be used to equip young people with the competences needed for participating actively in democratic culture, for respecting, promoting and defending human rights, and for engaging in respectful, appropriate and effective intercultural dialogue. It also provides guidance on how education can be used to equip young people with the competences that confer resilience to radicalization, violent extremist propaganda and hate speech.

\section{Underlying arguments made by the RFCDC}

There are three underlying arguments made by the RFCDC that are especially important to note. First, the RFCDC argues that a democratic culture is essential for the effective functioning of democracy. This is because although democracy cannot exist without democratic institutions, those institutions cannot work in practice unless citizens hold democratic values, attitudes and practices. In other words, a properly functioning democracy requires citizens to have a commitment to democratic processes, a willingness to express their opinions, a willingness to listen to the opinions of others, a commitment to decisions being made by majorities, a commitment to the protection of minorities and their rights, and a conviction that conflicts must be resolved peacefully. If citizens do not hold these democratic values and attitudes that is, if a democratic culture does not prevail - then democratic institutions will be unable to function effectively (compare with Wright, 2019, who has also recently argued that, in the current political climate, it is essential to defend and nourish not only the institutions of representative democracy but also the culture of democracy).

Second, the RFCDC proposes that democratic culture within culturally diverse societies requires intercultural dialogue. A fundamental principle of democracy is that the people who are affected by political decisions should be able to express their views when those decisions are being made, and that decision-makers should pay attention to those views when making their decisions. Intercultural dialogue is the means through which citizens can express their opinions, concerns and aspirations to other people who have different cultural affiliations from themselves. In other words, in the case of culturally diverse societies, intercultural dialogue is vital for democratic discussion, debate and deliberation, and for enabling all citizens to contribute to political decision-making on an equal footing, irrespective of their specific cultural affiliations (compare with Cantle, 2012, and Wilson, 2018, both of whom also argue that intercultural dialogue is vital for the full integration and inclusion of all citizens within culturally diverse democratic societies). For this reason, citizens need to be not only democratically competent but also interculturally competent to enable them to engage in intercultural dialogue.

A third argument made by the RFCDC is that democratic culture must be grounded in human rights. Human rights are essential for a just and cohesive society in which all citizens feel a sense of belonging and have their inherent dignity acknowledged and respected by their fellow citizens and by the state (compare with Donnelly, 2013, who similarly argues that human rights and democracy have deep conceptual and practical affinities, and are mutually reinforcing in liberal democracies). In the absence 
of respect for the dignity and human rights of other people, appropriate and effective intercultural dialogue will not be possible, democratic culture will not prevail, and democratic institutions and processes will not be able to function. From the point of view of the RFCDC, human rights, democracy, democratic culture and intercultural dialogue are intrinsically linked.

\section{An overview of the contents of the RFCDC}

The RFCDC provides educators with tools that can be used to empower learners by equipping them with the competences required for participation in democratic culture and intercultural dialogue. The goal is to enable learners to engage in respectful, appropriate and effective democratic and intercultural behaviour in realworld situations that they encounter in everyday life. Crucially, as a competence-based approach to citizenship education, it specifies what learners are expected to do rather than what they are expected to know (Gervais, 2016; Jonnaert et al., 2007; Kennedy et al., 2009; Soare, 2015). Competence-based curricula need to be learner-centred and tailored to the needs of learners within the particular society and context in which they are living. In addition, for a competence-based approach to be used in practice, it is necessary to specify: the particular set of competences that learners need to acquire in order to behave effectively and appropriately within real-world situations; descriptors of the different levels of proficiency that a learner may exhibit in each individual competence; learning outcomes that are linked to the ability to perform successfully in real-world situations; the types of learning experiences that can enable learners to achieve these learning outcomes; and methods of assessment that can be used to determine which learning outcomes need to be targeted as learning objectives in the next phase of learning (formative assessment) and which learning outcomes have been achieved at the end of a period of learning (summative assessment). The RFCDC provides all of these elements.

The RFCDC consists of three main components: a conceptual model of the competences that young people need to acquire; validated and scaled descriptors and learning outcomes for all of these competences; and guidance for ministries of education and education practitioners on curriculum, pedagogy, assessment, teacher education, the whole-school approach, and how to build learners' resilience to radicalization.

The first component of the RFCDC, the conceptual model of competences, contains 20 competences that fall into four broad categories: values, attitudes, skills, and knowledge and critical understanding (see Figure 1). These competences are the psychological resources that learners need to acquire if they are to respond appropriately and effectively to the demands, challenges and opportunities that are presented by democratic and intercultural situations. Each of the 20 competences is described in detail by the RFCDC (see Barrett, 2016a; Barrett et al., 2018a). Some of the competences (for example, openness and empathy) can be targeted from a relatively early age at pre-school and primary school, whereas others are more suitable for targeting in upper secondary school or even in higher education (for example, knowledge and critical understanding of politics, law and economies). As such, the RFCDC proposes that promoting the development of these competences is a task that applies across all levels of formal education, from pre-school through primary and secondary education to higher education. 


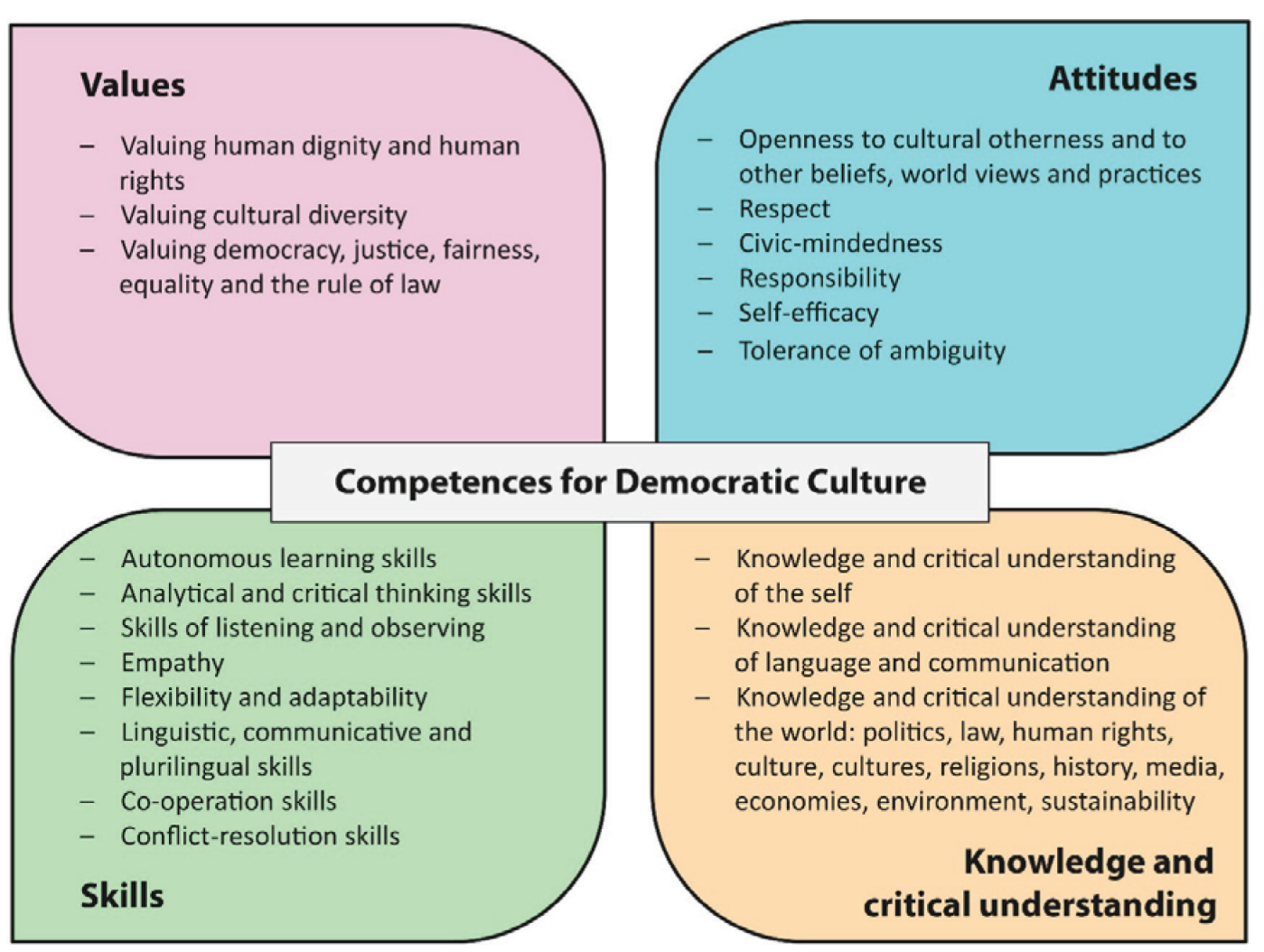

Figure 1: The RFCDC conceptual model of democratic and intercultural competence Figure reproduced from Barrett (2016a) (C) Council of Europe, reproduced with permission.

The RFCDC proposes that, in real-life situations, these 20 competences are rarely mobilized and used individually. Instead, they are much more likely to be deployed in clusters. Depending on the situation and the specific demands, challenges and opportunities which that situation presents, as well as the specific needs of the individual within the situation, different subsets of competences will be activated and deployed. Furthermore, any given situation also changes over time. For this reason, an effective adaptive response requires the constant monitoring of the situation and the appropriate ongoing adjustment of the competences being deployed. In other words, a competent individual mobilizes and deploys competences in a fluid, dynamic and adaptive manner in order to meet the constantly shifting demands, challenges and opportunities that arise in democratic and intercultural situations (compare with Jonnaert et al., 2007; Rychen and Salganik, 2003).

The second component of the RFCDC consists of the validated and scaled descriptors (Barrett et al., 2018b). These descriptors are clear, explicit and concise statements or descriptions of the observable behaviours that a person will display if they have achieved a certain level of proficiency in a given competence - in other words, they are indicators of an individual's level of achievement in that competence (see Box 1 for some examples). Importantly, the descriptors have been formulated using the language of learning outcomes: each descriptor contains an action verb and the object of that verb, and the behaviour that is described is both observable and assessable. Because they are expressed in the language of learning outcomes, the descriptors can be used not only for assessment purposes but also for curriculum development and pedagogical planning. 


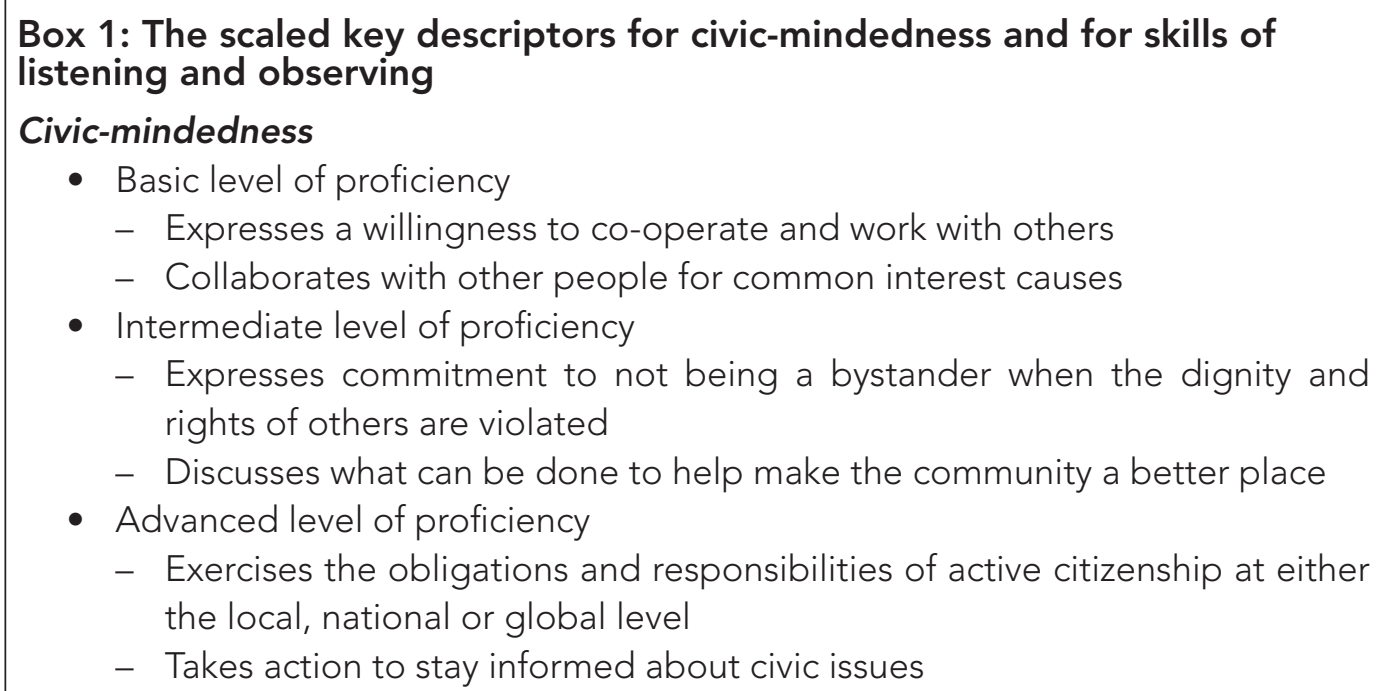

\section{Skills of listening and observing}

- Basic level of proficiency

- Listens attentively to other people

- Listens carefully to differing opinions

- Intermediate level of proficiency

- Can listen effectively in order to decipher another person's meanings and intentions

- Watches speakers' gestures and general body language to help himself/ herself to figure out the meaning of what they are saying

- Advanced level of proficiency

- Pays attention to what other people imply but do not say

- Notices how people with other cultural affiliations react in different ways to the same situation

Text reproduced from Barrett et al. (2018b) (C) Council of Europe, reproduced with permission.

The third component of the RFCDC consists of the guidance on how the conceptual model and the descriptors can be used by ministries of education and education practitioners (Barrett et al., 2018c).

The guidance on curriculum reviews the basic principles of curriculum design, and explains how the model of competences and the descriptors can be used for auditing and reviewing the prescribed curriculum in order to discover where democratic and intercultural competences are already being targeted as learning outcomes, and to identify where else in the curriculum the 20 competences could also be targeted. It also discusses how to develop the current curriculum, if this is necessary and possible, to ensure that all 20 competences are being fostered in learners.

A significant focus of the guidance on the curriculum is how to develop a crosscurricular approach, in which the responsibility for fostering democratic and intercultural competences is distributed and incorporated across the entire school curriculum. It is important to note that the competences that are specified by the RFCDC can in fact be targeted by every school subject. For example, even subjects such as mathematics and the natural sciences can make a contribution if they employ co-operative group work that requires learners to practise their listening and observing, communication, empathy, respect, co-operation and conflict-resolution skills. 
The guidance on pedagogy discusses the principles of pedagogical planning, and reviews the teaching and learning methods that are suitable for fostering the development of democratic and intercultural competences in learners. These include: teachers modelling democratic attitudes and behaviours; implementing democratic processes in the classroom by involving learners in making decisions about activities, responsibilities and rules; using activities that are based on co-operative group work; using project-based learning; and using service learning.

The guidance on assessment examines the basic principles of assessment, and explores various conceptual distinctions including high-stakes versus low-stakes assessment, achievement versus proficiency assessment, norm-referenced versus criterion-referenced assessment, and formative versus summative assessment. The guidance also reviews the methods that are suitable for assessing the development of democratic and intercultural competences in learners. These include: open-ended diaries, reflective journals and structured autobiographical reflections; observational assessment; dynamic assessment; project-based assessment; and portfolio assessment.

In addition, the guidance on assessment considers issues concerning the assessment of learners' values and attitudes. It is noted that all assessment procedures that are used in connection with the RFCDC should respect the dignity and the rights of the learner who is being assessed. These rights are defined by the European Convention on Human Rights (CoE, 2013b) and the Convention on the Rights of the Child (United Nations, 1990). They include, inter alia, the rights to freedom of thought, conscience and religion, freedom of expression, and freedom from discrimination. Assessment procedures (and indeed any other education practices) that violate one or more of these rights of learners should not be used. Indeed, the European Court of Human Rights (2019) explicitly allows freedom of expression even in cases where the views expressed are regarded as offensive, shocking or disturbing, because freedom of expression constitutes one of the essential foundations of a democratic society. Hence, learners should not be sanctioned or censured in an assessment because the views which they express are offensive, shocking or disturbing. However, the European Court also holds that, in the case of forms of expression that spread, incite, promote or justify hatred based on intolerance, it may be necessary to sanction or even prevent such forms of expression. This is because tolerance and respect for the equal dignity of all human beings constitute another essential foundation for democratic societies. In other words, learners may be censured in an assessment if the expression of their views spreads, incites, promotes or justifies hatred based on intolerance. The guidance on assessment recommends that, if learners do express hate speech in an assessment, they should be challenged, and these expressions should be used as a learning opportunity to help the learner to develop greater respect for the dignity and rights of others.

Implementing the RFCDC requires changing many aspects of school life, and teachers need to be prepared for managing these changes. The guidance on teacher education discusses the role of both pre-service and in-service teacher education in promoting and implementing education based on the RFCDC. The guidance suggests that, because education based on the RFCDC is most effective when delivered using a cross-curricular approach, the responsibility for delivering it should not be assigned solely to subject-specific specialists such as teachers of civic education or social studies, but should be shared by all teachers, irrespective of the specific school subject they teach. For this reason, teacher education needs to ensure that all teachers understand the principles of the RFCDC and are proficient in applying these principles in the course of their everyday planning and practice. The guidance on teacher education also emphasizes that, in order to be able to educate children and young people in 
ways that foster the development of the competences, it is essential that teachers themselves acquire democratic and intercultural competences. This also applies to teacher educators.

The guidance on the whole-school approach explains the importance of creating an institutional environment in which democratically and interculturally appropriate and respectful principles and practices permeate all aspects of institutional life. In other words, these principles should be used in: curriculum development; the teaching and learning methods and resources that are used; the assessment methods that are used; school leadership, governance and decision-making; staff-staff, staff-student and student-student relationships; extracurricular activities; and links with the community.

The benefits of using a whole-school approach to teach values such as human rights, respect, responsibility, justice, fairness and equality are well-established. These benefits include: more respectful and harmonious social relationships within the school; increased learner responsibility, self-efficacy, self-esteem and intrinsic motivation; improvements in learning and academic standards; better understanding by learners of the nature of rights and responsibilities; learners participating actively in decisionmaking in the school; learners being empowered to undertake action in defence of human rights; and learners acquiring more positive attitudes towards diversity (for evidence of these various benefits of using a whole-school approach in human rights and values education, see Covell and Howe, 2001, 2008; Lovat, 2017; Lovat and Hawkes, 2013; Sebba and Robinson, 2010). The guidance on the whole-school approach provides practical recommendations on how a whole-school approach may be introduced and applied within a school.

Finally, the guidance on radicalization explains how the RFCDC can help to build learners' resilience to radicalization. The RFCDC contributes to this goal because it equips learners not only with the competences needed for democratic culture and intercultural dialogue, but also with the competences needed for recognizing and dealing with extremist and terrorist propaganda (for example, analytical and critical thinking skills, knowledge and critical understanding of media) and for valuing human dignity, human rights and democratic processes. The guidance explains what is known from research about how resilience to radicalization can be built. Actions that can be taken include, for example, training learners to use more complex critical thinking skills (for example, Liht and Savage, 2013), and promoting their empathy through structured social-cognitive activities (Beelmann, 2009). All of the actions that have been found to be effective for building resilience involve fostering one or more of the specific competences that are included within the RFCDC. In other words, education based on the RFCDC provides a much more systematic, comprehensive and powerful method for building learners' resilience to radicalization than any of these individual actions that have been identified by research.

Because the RFCDC is intended as a tool to help education policymakers and practitioners to rethink their existing activities in the fields of citizenship, human rights and intercultural education, the guidance that is offered on each of these various topics is open-ended. Essentially, the guidance identifies the various options that may be used to implement the RFCDC and outlines the pros and cons of each option. The user is then invited to consider the relevant issues and to make their own decisions in light of those considerations. All decision-making is very deliberately left to local policymakers and practitioners, who are the ones who have the detailed understanding of the national and cultural contexts in which they are operating - they are therefore the relevant individuals who will need to make decisions concerning implementation that are suitable for and tailored to their own societies, education systems and contexts. 


\section{The impact of the RFCDC on CoE actions in the sphere of formal education}

The importance of the RFCDC as a vehicle for delivering EDC/HRE and IE in the member states was recognized before its finalization and formal publication. For example, there was extensive discussion of the RFCDC at the CoE's Conference on the Future of Citizenship and Human Rights Education in Europe, which was held in Strasbourg in June 2017. The aim of this conference was to explore how the EDC/HRE Charter (CoE, 2010) could be further strengthened as a support tool for building democratic societies based on respect for human rights. As the final report on the conference observed (Perona, 2017), the participants highlighted the need to link the provision of EDC/HRE at all levels to the RFCDC, the role that the RFCDC can play in bringing EDC/HRE closer to teachers' practice, and the fact that the Charter's objectives and principles can be put into practice much more effectively with the help of the RFCDC.

In order to encourage and support the implementation of the RFCDC within the member states, two significant actions were subsequently undertaken by the CoE. First, alongside the publication and launch of the RFCDC itself at the Conference of the Danish Chairmanship of the Committee of Ministers in April 2018, a new Education Policy Advisors Network (EPAN) was also launched. EPAN replaced the older network of national EDC/HRE coordinators. The terms of reference of EPAN include encouraging integration of the RFCDC into the education systems of the member states, and sharing effective practices and strategies for the implementation of the RFCDC. Each member state has two to three representatives on EPAN, who are typically either senior civil servants from the ministry of education, senior academics in the field of education, or members of a relevant professional body. They are nominated for membership of EPAN by their ministries of education. EPAN meets approximately three times per year to discuss strategies and practices for implementing the RFCDC, and to offer support and advice to member states on their implementation activities.

In addition, in November 2018, at a conference held in Oslo to celebrate the tenth anniversary of the European Wergeland Centre, a new CoE Democratic Schools Network was launched. Individual schools in all of the CoE's member states may join and participate in this network. In order to do so, they must commit to the CoE's Democratic Schools Pledge, and submit a relevant new or ongoing project involving the implementation of the RFCDC. Membership of the network enables schools to access teacher training opportunities, webinars and tutorials on the implementation of the RFCDC, a toolkit and publications, and opportunities for networking, showcasing and sharing their work. The network aims to draw together good practices that are identified by schools themselves, and to empower and give voice to education practitioners and school students in providing input to policymakers on the challenges involved in implementing the RFCDC and the strategies that may be used to tackle these challenges.

In April 2019, EPAN conducted a survey of the member states, to take stock of the extent to which they were using the RFCDC. The returns revealed that, just one year after its publication, the RFCDC had already been implemented in Andorra, was being implemented in Azerbaijan, Belarus, Cyprus, Finland, Greece, Moldova, Montenegro, Portugal, San Marino, Serbia and Ukraine, and was being partly implemented in Belgium (French-speaking community), Italy, Latvia, North Macedonia and Romania - that is, in 17 countries in total. From the survey returns, it was apparent that, as expected, different countries were adopting different approaches to implementation, tailoring the RFCDC to their own particular education systems and national and cultural 
contexts. Evaluation studies will be required in the future to ascertain the mode and manner of implementation that is the most effective for enhancing the competences of learners in particular contexts.

The EPAN survey also revealed that challenges were being encountered in trying to implement the RFCDC, with these challenges varying from country to country. Five of the 17 countries reported no significant obstacles to implementation - these tended to be countries in which the RFCDC was being implemented as part of the standard cycle of curriculum review and reform, with backing from the ministry of education. The challenges identified in the other countries included:

- inadequate or insufficient training courses on the RFCDC for school principals and teachers to enable them to support implementation

- teachers' perceptions of their role as transmitters of knowledge rather than as promoters of learners' competences

- resistance from those school principals and teachers whose main focus was on learners' academic achievements and test results

- the workload of school principals and teachers, reducing their motivation to engage in innovative reform

- opposition from teachers' trade unions

- a lack of school textbooks employing a competence-based approach

- parents' resistance to the introduction of a new way of assessing learners' proficiency that does not result in the awarding of grades.

Many of these challenges are similar to those that tend to characterize educational change and innovation more generally (Hargreaves et al., 2010; Serdyukov, 2017).

Strategies that were being used to respond to these challenges also varied across countries, depending on the specific challenges that were being encountered. The strategies included:

- significantly expanding the provision of pre-service and in-service teacher education courses on the RFCDC

- using consultation, negotiation and persuasion with school principals, teachers, trade unions or parents, as appropriate

- adapting the RFCDC to national circumstances, and working only with those parts of the RFCDC that are directly relevant to the national agenda, needs and priorities

- revising existing textbooks and other educational materials, and designing new textbooks and materials

- national experts publishing awareness-raising articles about the RFCDC in both academic and professional outlets within their own countries.

In addition, EPAN is currently in the process of producing further, more detailed guidance materials for member states, focusing in particular on how to implement the RFCDC in the curriculum, teaching and learning, assessment, and teacher education.

\section{Conclusion}

The RFCDC provides a systematic approach to designing the teaching, learning and assessment of competences for democratic culture and intercultural dialogue, and introducing these competences into education systems in ways that are coherent and comprehensive. It has become clear over the past three years that there is a significant political will to implement the RFCDC in a large number of European countries. 
Implementation faces various challenges, but strategies for tackling these challenges are being identified. It is hoped that education decision-making and planning in all member states of the CoE - and indeed in other countries beyond the CoE - will eventually benefit from the implementation of the RFCDC, so that all of these states can harness their education systems for the purpose of preparing learners for civic and political life and empowering them as democratically and interculturally competent citizens.

\section{Notes on the contributor}

Martyn Barrett is Emeritus Professor of Psychology at the University of Surrey. He obtained his degrees from the Universities of Cambridge and Sussex. His research examines the development of intercultural, democratic and global competence; young people's political and civic engagement and global citizenship; and the development of young people's national and ethnic identifications, prejudice, stereotyping and attitudes. He works as an expert for the Council of Europe and for the OECD PISA programme.

\section{References}

Bäckman, E. and Trafford, B. (2007) Democratic Governance of Schools. Strasbourg: Council of Europe Publishing. Online. https://tinyurl.com/rbt9ua2 (accessed 30 November 2019).

Barrett, M. (2013) 'Introduction: Interculturalism and multiculturalism: Concepts and controversies'. In Barrett, M. (ed.) Interculturalism and Multiculturalism: Similarities and differences. Strasbourg: Council of Europe Publishing, 15-42.

Barrett, M. (2016a) Competences for Democratic Culture: Living together as equals in culturally diverse democratic societies. Strasbourg: Council of Europe Publishing. Online. https://rm.coe.int/16806ccc07 (accessed 1 December 2019).

Barrett, M. (2016b) Hearing on the Assessment of Competences for Democratic Culture (CDC): Report by the General Rapporteur. Strasbourg: Council of Europe.

Barrett, M., Byram, M., Ipgrave, J. and Seurrat, A. (2013) Images of Others: An autobiography of intercultural encounters through visual media. Strasbourg: Council of Europe Publishing. Online. https://tinyurl.com/t27wygv (accessed 1 December 2019).

Barrett, M., Byram, M., Lázár, I., Mompoint-Gaillard, P. and Philippou, S. (2014) Developing Intercultural Competence through Education (Pestalozzi Series No. 3). Ed. Huber, J. and Reynolds, C. Strasbourg: Council of Europe Publishing. Online. https://tinyurl.com/s6depgg (accessed 1 December 2019).

Barrett, M., De Bivar Black, L., Byram, M., Faltýn, J., Gudmundson, L., Van't Land, H., Lenz, C., Mompoint-Gaillard, P., Popović, M., Rus, C., Sala, S., Voskresenskaya, N. and Zgaga, P. (2018a) Reference Framework of Competences for Democratic Culture: Volume 1: Context, concepts and model. Strasbourg: Council of Europe Publishing. Online. https://tinyurl.com/wuobmhj (accessed 1 December 2019).

Barrett, M., De Bivar Black, L., Byram, M., Faltýn, J., Gudmundson, L., Van't Land, H., Lenz, C., Mompoint-Gaillard, P., Popović, M., Rus, C., Sala, S., Voskresenskaya, N. and Zgaga, P. (2018b) Reference Framework of Competences for Democratic Culture: Volume 2: Descriptors of competences for democratic culture. Strasbourg: Council of Europe Publishing. Online. https://tinyurl.com/tzd9nwq (accessed 1 December 2019).

Barrett, M., De Bivar Black, L., Byram, M., Faltýn, J., Gudmundson, L., Van't Land, H., Lenz, C., Mompoint-Gaillard, P., Popović, M., Rus, C., Sala, S., Voskresenskaya, N. and Zgaga, P. (2018c) Reference Framework of Competences for Democratic Culture: Volume 3: Guidance for implementation. Strasbourg: Council of Europe Publishing. Online. https://tinyurl.com/urpvnqk (accessed 1 December 2019).

Beelmann, A. (2009) 'Prevention of right-wing extremism: European and international research results'. In Niggli, M.A. (ed.) Right-Wing Extremism in Switzerland: National and international perspectives. Baden-Baden: Nomos, 252-64. 
Bîrzea, C., Cecchini, M., Harrison, C., Krek, J. and Spajić-Vrkaš, V. (2005) Tool for Quality Assurance of Education for Democratic Citizenship in Schools. Paris: United Nations Educational, Scientific and Cultural Organization. Online. https://unesdoc.unesco.org/ark:/48223/pf0000140827_eng (accessed 1 December 2019).

Bunjes, U. (2013) 'The intercultural milestone: The history of the Council of Europe's White Paper on Intercultural Dialogue'. In Barrett, M. (ed.) Interculturalism and Multiculturalism: Similarities and differences. Strasbourg: Council of Europe Publishing, 43-52.

Byram, M., Barrett, M., Davcheva, L., Gomez Mejia, G., Ipgrave, J., Lindner, R. and Seurrat, A. (in press) Autobiography of Intercultural Encounters through the Internet. Strasbourg: Council of Europe Publishing.

Byram, M., Barrett, M., Ipgrave, J., Jackson, R. and Del Carmen Méndez García, M. (2009) Autobiography of Intercultural Encounters. Strasbourg: Council of Europe Publishing. Online. https://tinyurl.com/rs89nf8 (accessed 1 December 2019).

Byram, M. and Parmenter, L. (eds) (2012) The Common European Framework of Reference: The globalisation of language education policy. Bristol: Multilingual Matters.

Cameron, D. (2011) 'PM's speech at Munich Security Conference'. Online. https://tinyurl.com/kgzpots (accessed 1 December 2019).

Cantle, T. (2012) Interculturalism: The new era of cohesion and diversity. Basingstoke: Palgrave Macmillan.

CoE (Council of Europe) (2001) Common European Framework of Reference for Languages: Learning, teaching, assessment. Cambridge: Cambridge University Press. Online. https://rm.coe.int/16802fc1bf (accessed 1 December 2019).

CoE (Council of Europe) (2008) White Paper on Intercultural Dialogue: "Living together as equals in dignity". Strasbourg: Council of Europe. Online. https://tinyurl.com/736wce6 (accessed 1 December 2019)

CoE (Council of Europe) (2010) Council of Europe Charter on Education for Democratic Citizenship and Human Rights Education. Strasbourg: Council of Europe Publishing. Online. https://tinyurl.com/ubdymoh (accessed 1 December 2019).

CoE (Council of Europe) (2011) Living Together: Combining diversity and freedom in 21st-century Europe: Report of the Group of Eminent Persons of the Council of Europe. Strasbourg: Council of Europe. Online. https://rm.coe.int/16806b97c5 (accessed 1 December 2019).

CoE (Council of Europe) (2013a) Council of Europe Standing Conference of Ministers of Education: "Governance and Quality Education" - 24th Session: Helsinki, Finland, 26-27 April 2013: Final declaration on the conference theme. Strasbourg: Council of Europe. Online. https://tinyurl.com/uxa7780 (accessed 1 December 2019).

CoE (Council of Europe) (2013b) European Convention on Human Rights. Strasbourg: Council of Europe. Online. www.echr.coe.int/Documents/Convention_ENG.pdf (accessed 26 August 2019).

CoE (Council of Europe) (2015) 'The fight against violent extremism and radicalisation leading to terrorism - action plan (Committee of Ministers Document CM(2015)74)'. Online. https://tinyurl.com/u2t54tj (accessed 1 December 2019).

CoE (Council of Europe) (2016) Council of Europe Standing Conference of Ministers of Education: "Securing Democracy through Education: The development of a reference framework of competences for democratic culture" - 25th Session: Brussels, 11-12 April 2016: Final declaration on the conference theme. Strasbourg: Council of Europe. Online. https://tinyurl.com/vsfsqgs (accessed 1 December 2019).

Covell, K. and Howe, R.B. (2001) 'Moral education through the 3 Rs: Rights, respect and responsibility'. Journal of Moral Education, 30 (1), 29-41.

Covell, K. and Howe, R.B. (2008) Rights, Respect and Responsibility: Final report on the County of Hampshire Rights Education Initiative. Sydney, NS: Cape Breton University. Online. https://tinyurl.com/taaw3oa (accessed 1 December 2019).

Donnelly, J. (2013) Universal Human Rights in Theory and Practice. 3rd ed. Ithaca, NY: Cornell University Press.

European Court of Human Rights (2019) Hate Speech. Strasbourg: Council of Europe. Online. www.echr.coe.int/Documents/FS_Hate_speech_ENG.pdf (accessed 1 December 2019).

Gervais, J. (2016) 'The operational definition of competency-based education'. Journal of Competency-Based Education, 1 (2), 98-106.

Gollob, R. and Krapf, P. (eds) (2008) Living in Democracy: EDC/HRE lesson plans for lower secondary level. Strasbourg: Council of Europe Publishing.

Gollob, R., Krapf, P. and Weidinger, W. (eds) (2010a) Growing up in Democracy: Lesson plans for primary level on democratic citizenship and human rights. Strasbourg: Council of Europe Publishing. 
Gollob, R., Krapf, P. and Weidinger, W. (eds) (2010b) Taking Part in Democracy: Lesson plans for upper secondary level on democratic citizenship and human rights education. Strasbourg: Council of Europe Publishing.

Hargreaves, A., Lieberman, A., Fullan, M. and Hopkins, D. (eds) (2010) Second International Handbook of Educational Change. Dordrecht: Springer.

Jonnaert, P., Masciotra, D., Barrette, J., Morel, D. and Mane, Y. (2007) 'From competence in the curriculum to competence in action'. Prospects, 37 (2), 187-203.

Kennedy, D., Hyland, Á. and Ryan, N. (2009) 'Learning outcomes and competences'. In Kennedy, D., Hyland, Á., Ryan, N., Gehmlich, V. and Balissa, A. Using Learning Outcomes (Best of the Bologna Handbook 33). Berlin: Raabe Verlag, 59-76.

Kerr, D., Losito, B., Sanchez, R., Hoskins, B., Smirnov, W. and Krek, J. (2010) Strategic Support for Decision Makers: Policy tool for education for democratic citizenship and human rights. Strasbourg: Council of Europe Publishing.

Liht, J. and Savage, S. (2013) 'Preventing violent extremism through value complexity: Being Muslim being British'. Journal of Strategic Security, 6 (4), 44-66.

Lovat, T. (2017) 'Values education as good practice pedagogy: Evidence from Australian empirical research'. Journal of Moral Education, 46 (1), 88-96.

Lovat, T. and Hawkes, N. (2013) 'Values education: A pedagogical imperative for student wellbeing'. Educational Research International, 2 (2), 1-6.

Merkel, A. (2010) Speech to the Conference of the Youth Wing of the Christian Democratic Union party, 17 October 2010.

Perona, A. (2017) Learning to Live Together: A shared commitment to democracy-Conference on the Future of Citizenship and Human Rights Education in Europe, Strasbourg, 20-22 June 2017: General report. Strasbourg: Council of Europe. Online. https://tinyurl.com/v66y68s (accessed 1 December 2019).

Rychen, D.S. and Salganik, L.H. (eds) (2003) Key Competencies for a Successful Life and a WellFunctioning Society. Cambridge, MA: Hogrefe and Huber.

Sarkozy, N. (2011) Televised interview, Paroles de Français, TF1, 10 February 2011.

Sebba, J. and Robinson, C. (2010) Evaluation of UNICEF UK's Rights Respecting Schools Award: Final report. London: UNICEF UK. Online. https://tinyurl.com/wyabw7u (accessed 1 December 2019).

Serdyukov, P. (2017) 'Innovation in education: What works, what doesn't, and what to do about it?' Journal of Research in Innovative Teaching and Learning, 10 (1), 4-33.

Soare, E. (2015) 'Perspectives on designing the competence based curriculum'. Procedia - Social and Behavioral Sciences, 180, 972-7.

United Nations (1990) 'Convention on the Rights of the Child'. Online. www.ohchr.org/Documents/Professionallnterest/crc.pdf (accessed 26 August 2019).

Van't Land, H. (2013) High-Level Conference on "Competences for a Culture of Democracy and Intercultural Dialogue: A political challenge and values", Andorra la Vella, Andorra, 7-8 February 2013: General Report. Strasbourg: Council of Europe.

Wilson, R. (2018) Meeting the Challenge of Cultural Diversity in Europe: Moving beyond the crisis. Cheltenham: Edward Elgar Publishing.

Wright, T. (2019) 'Democracy and its discontents'. In Gamble, A. and Wright, T. (eds) Rethinking Democracy. Chichester: Wiley, 5-17. 